\title{
THE EFFECTS OF SPINAL ANESTHESIA ON THE CIRCULATION IN NORMAL, UNOPERATED MAN WITH REFERENCE TO THE AUTONOMY OF THE ARTERIOLES, AND ESPECIALLY THOSE OF THE RENAL CIRCULATION
}

\author{
By H. W. SMITH, E. A. ROVENSTINE, W. GOLDRING, H. CHASIS, AND \\ H. A. RANGES \\ (From the Departments of Physiology, Anesthesia, and Medicine, New York University College \\ of Medicine, and the Third (New York University) Division of \\ Bellerue Hospital, New York City)
}

(Received for publication February 1, 1939)

The present study, comprising observations on 21 subjects given high spinal anesthesia, is an investigation of the effects of anesthetic denervation in normal man, uncomplicated by surgical intervention, on the circulation with particular reference to the vascular bed of the kidney. It is concluded that the renal arterioles are distinctly autonomous, in the sense that under basal conditions the renal vascular tone is not affected by anesthetic denervation. Our observations further suggest that the arteriolar bed generally (apart from the skin) possesses considerably more autonomy than is usually attributed to it-sufficient, in fact, in the normal supine individual at rest, to maintain an essentially normal arterial pressure. We find no evidence of significant arteriolar dilatation during high spinal anesthesia, such reduction in blood pressure as occurs being attributable, we believe, to diminished circulating blood volume in consequence of dilatation of the capillaries, venules, and veins.

Part I deals with the following topics: (1) Methods; (2) the effects of spinal anesthesia on renal blood flow; (3) on the arterial pressure, and (4) on the reflex responses to posture, hypercapnia, and anoxemia. Part II consists of a review of the evidence on (5) the existence of tonic vasoconstrictor activity and on (6) the existence of autonomy in the peripheral arterioles generally, and $(7)$ in the kidney in particular, and $(8)$ the peripheral effects of hypercapnia and anoxemia. In (5) it is brought out that the notion of tonic vasoconstrictor activity in the sympathetic nervous system, apart from the skin, is based largely upon animal experiments which are seriously complicated by general anesthesia, venous dilatation, etc., and that the information so obtained cannot be transferred with confidence to normal animals, and certainly not to man.

\section{PART I}

\section{Methods}

The subjects were male convalescent patients ranging in age from 18 to 50 years who, with a single exception, presented no abnormal signs contraindicating selection for this study. They were examined in the morning in the basal, fasting condition, and were prepared for the measurement of renal blood flow and filtration rate by the clearance method, as described by Smith, Goldring, and Chasis (93). In the earlier observations the phenol red and inulin (35) clearances were followed, but after the introduction of the diodrast clearance (93), all three clearances were used. The phenol red clearance serves as a check on the diodrast clearance, the constancy of the phenol red/diodrast clearance ratio before and after anesthesia demonstrating that procaine per se has no effect upon the tubular excretory mechanism. The infusions corresponded to the typical infusion cited by Chasis, Ranges, Goldring, and Smith (18). Zero time was taken as the beginning of the priming infusion, which occupied about 10 minutes; the infusion was then changed to the sustaining infusion, the first urine collection period being started at about 30 minutes. The sustaining infusion was usually interrupted momentarily to permit injection of the anesthetic, and a short washout period was allowed to reestablish blood levels of diodrast, etc. before the next urine collection period was started. The urine collection periods (10 to 15 minutes in length) were timed to 15 seconds, and all urine samples were collected by catheter with sterile precautions, the bladder being washed out with $20 \mathrm{cc}$. of saline. (In our opinion, single urine collection periods obtained by voluntary voiding, or even by catheterization without rinsing the bladder, may be highly inaccurate; we have made nearly 3000 catheterized and rinsed collections, and we recognize that it is impossible even by this method to empty the bladder completely every time.) All our observations have been made on the descending limb of water diuresis, and to prevent an excessive reduction of urine flow we have 
usually incorporated 2.0 per cent $\mathrm{Na}_{2} \mathrm{SO}_{4}$ in the infusion fluid. Analyses were carried out as described by Smith, Goldring, and Chasis (93), except that phenol red was determined on an Evelyn colorimeter, using a Number 540 filter.

Anesthesia was induced by an experienced anesthetist (E. R.) by the intrathecal injection between L3 and L4 (after local anesthesia of the skin) of procaine crystals (= novocaine) dissolved in 2 to 5 cc. of spinal fluid. No premedication was given. The quantities of procaine used were somewhat larger than the usual surgical dose, since we wished to obtain maximal anesthesia. In earlier instances the injection was made with the subject in the lateral position, after which he was immediately turned to the supine and tilted at an angle of $-20^{\circ}$ to $-10^{\circ}$ until the highest level of anesthesia was established. However, it is impossible by this method to be certain that the anterior roots are exposed to maximal concentration of the anesthetic, and consequently in later observations the subject was injected in the prone position and left lying on his face until anesthesia had reached its highest point (5 to 10 minutes), after which he was turned on his back. Blood pressures were taken by auscultation of the brachial artery at. frequent intervals. The level of anesthesia was conservatively determined by sensory stimulation, the dermatomes being designated according to the recent description of Foerster (28). Complete loss of all sensation up to and including the umbilicus was taken to indicate anesthesia of the posterior roots up to and including $\mathrm{T} 12$; to the xiphoid process, T7; to just below the nipple, T6; to just above the nipple, T5; to the clavicle, T2; to the inner aspect of the forearm, $\mathrm{T} 1$; to the hollow above the clavicle and the outer shoulder, C4; to the neck, C3.

\section{The effects of anesthesia on renal blood flow}

Reflex oliguria and renal ischemia. The discussion of the effects of spinal anesthesia upon the renal circulation must be prefaced by brief mention of the reflex effects of spinal puncture per se on urine flow and renal blood flow. Spinal puncture is frequently accompanied by an abrupt reduction in urine flow and less frequently by a marked but transient reduction in renal clearances. We have noted that frequently, though not invariably, the urine flow has fallen abruptly at the time of puncture and remained at relatively low levels ( 0.5 to 2.5 cc. per minute) thereafter. Theobald and Verney (100) have shown in dogs that trauma of the vertebral periosteum causes an inhibition of urine excretion in the denervated kidney; they have interpreted this phenomenon to be a result of an increased secretion of the antidiuretic hormone in consequence of reflex excitation of the posterior pituitary gland, and it is probable that this explanation applies to those instances in our observations where the urine flow fell sharply at the time of puncture without a simultaneous change in clearances. We have never observed an increase in urine flow in consequence of spinal anesthesia; although not specifically designed to examine this question, we believe that our observations would have revealed any tendency for diuresis to occur, were such a tendency present. One of us has argued elsewhere (92) that "denervation diuresis" is a phenomenon which is discoverable only in the anesthetized animal and our present observations lead us to affirm that anesthetic denervation of the kidneys has no specific effect on water excretion.

In a few instances the diodrast, phenol red, and inulin clearances have fallen markedly at the time of spinal puncture, suggesting constriction of the renal arterioles in consequence of accidental traumatic excitation of the periosteum or nerve fibers in the spinal canal. This phenomenon may be elicited by a control puncture without the injection of any anesthetic, although it is not consistently reproducible even by a painful stimulus. Where such reduction in clearances occurs, the disturbance is fleeting (10 to 20 minutes), and in the data presented here we have excluded the first 20 to 30 minutes after puncture if any obvious disturbance did occur.

Renal blood flow. From previously published observations (18) and from unpublished data it can be stated that the blood flow through the normal human kidney under essentially constant arterial pressure can vary through a wide range, the extreme values observed by us to date in normal individuals being about 600 to $3000 \mathrm{cc}$. per minute. However, the renal blood flow tends to remain quite constant on any one day or on weekly re-examinations, unless it is altered by factors obviously of such a nature as to modify the renal circulation (adrenin and other drugs, pyrogenic reaction, etc.). When changes in the renal blood flow are so induced they are accompanied by changes in the filtration fraction, indicating a disturbance of the relative tonus of the afferent and efferent glomerular arterioles. The extreme values of the filtration fraction that we have observed under various circulatory conditions are about 0.08 and 0.33 .

From our present data on the effects of spinal 
anesthesia on renal blood flow we present in detail two series of observations in Figures 1 and 2, which are fully explained in the legends, and a summary of pertinent data on all subjects in Table I. (Six subjects in whom no clearances were determined during the pre-anesthesia control period are omitted from Table I; but this table includes 2 subjects who are not included in Figures 3 and 4, in whom anesthesia rose only to T6 and
T9 (Numbers 19 and 20).) Circulatory tests, as described in Section 4, were made upon a number of these subjects both before and during anesthesia ; in only a few instances did these tests have any apparent effect on the renal circulation, and in analyzing the data with respect to the effect of anesthesia upon renal blood flow we have with few exceptions compared the average of three clearance periods before anesthesia with the average

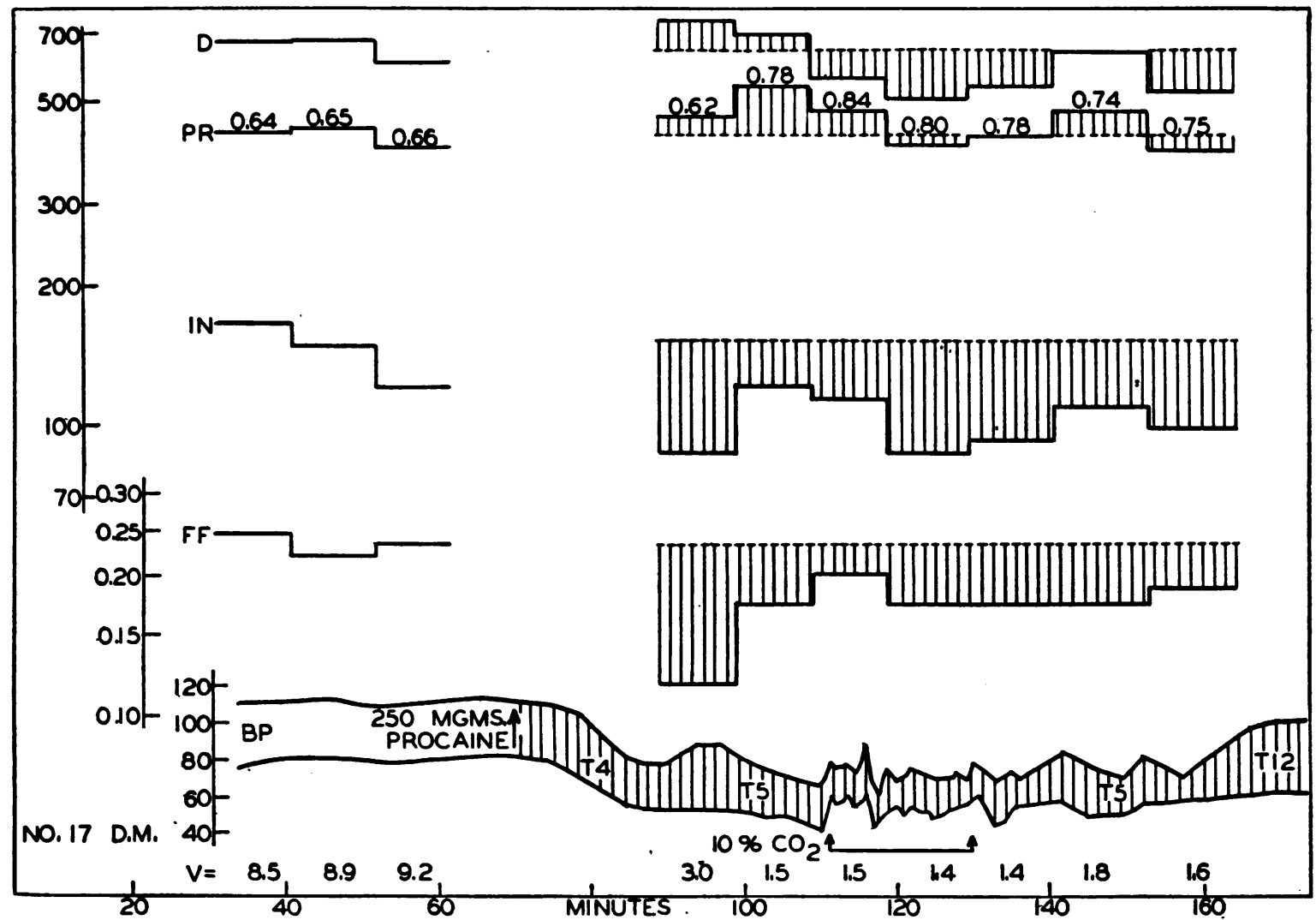

Fig. 1. The Effect of Spinal Anesthesia on Renal Function and Arterial Pressure in Subject 17

During the period indicated 10 per cent $\mathrm{CO}_{2}$ in air was administered by an anesthetic face mask. The data from above downward are:

$D$ : Diodrast plasma clearance $=$ effective renal plasma flow in cc. per minute.

$P R$ : Phenol red plasma clearance in cc. per minute. The figures above this curve indicate the $P R / D$ clearance ratio.

$I N$ : Inulin plasma clearance $=$ rate of glomerular filtration in cc. of plasma per minute.

$F F$ : Filtration fraction (i.e., fraction of plasma filtered through the glomeruli) $=I N / D$.

$B P$ : Auscultory brachial pressure in $\mathrm{mm}$. $\mathrm{Hg}$. The figures within the $B P$ curve show the spinal level of complete sensory anesthesia.

$V$ : Urine volume in cc. per minute.

This subject showed 8 per cent decrease in the mean renal plasma flow during anesthesia up to T5, as compared with the 3 control periods before anesthesia. The marked drop in the absolute filtration rate (33 per cent) and in the filtration fraction (27 per cent) is probably attributable to the fall in arterial pressure, the mean value of which decreased 33 per cent in consequence of anesthesia. This is the most marked fall in filtration rate observed, and should be compared with Figure 2, or the data in Table I. 


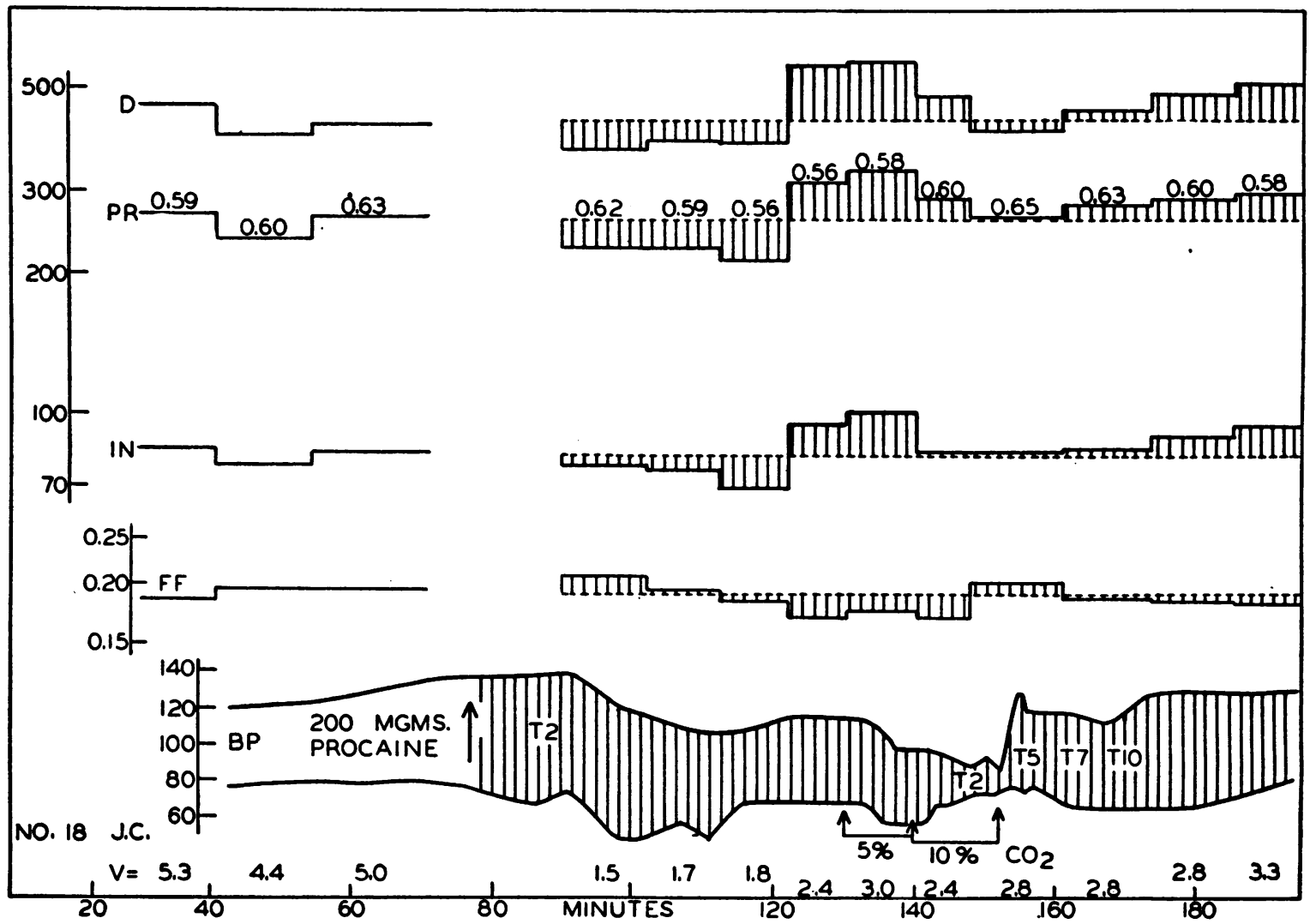

Fig. 2. The Effect of Spinal Anesthesia on Renal Function and Arterial Pressure IN SUBJECT 18

See Figure 1 for meaning of data. This subject showed an increase of 8 per cent in renal plasma flow and a 4 per cent decrease in filtration fraction during anesthesia up to T2. This response resembles the majority of those listed in Table I.

of all clearance periods while anesthesia was at its height.

If vasotonic impulses, necessary for maintenance of either afferent or efferent arteriolar tone, are carried to the kidneys by the sympathetic nerves, anesthetization of the spinal roots up to T5 or higher would be expected to result in changes of considerable magnitude both in the renal blood flow and in the filtration fraction. So long as the arterial pressure remains constant these changes would, in theory, be of the following qualitative nature: (a) Afferent dilatation alone would be accompanied by an increase in both the renal blood flow and the filtration fraction, the latter rising in consequence of increased glomerular pressure. (b) Efferent dilatation alone would be accompanied by an increase in the renal blood flow, but a decrease in the filtration fraction, the latter falling in consequence of a decrease in glomerular pressure. (c) Simultaneous afferent and efferent dilation should be accompanied by the greatest increase in renal blood flow without marked changes in the filtration fraction. (d) Apart from the foregoing factors, any change in arterial pressure would tend to change both the renal blood flow and the filtration fraction in the same direction. ${ }^{1}$

Applying these general propositions to the first

1 If equilibrium between the glomerular filtration pressure and capsular pressure is not normally reached before the blood emerges from the glomeruli, any change in the renal blood flow would itself alter the filtration fraction by prolonging the time of contact. The effects of variation in the time of contact and of filtration pressure would be in the same direction in consequence of changes in efferent arteriolar tone, and in the opposite direction in consequence of changes in afferent arteriolar tone. These two factors cannot be definitely separated at the present time. 
TABLE I

Effects of spinal anesthesia on renal blood flow

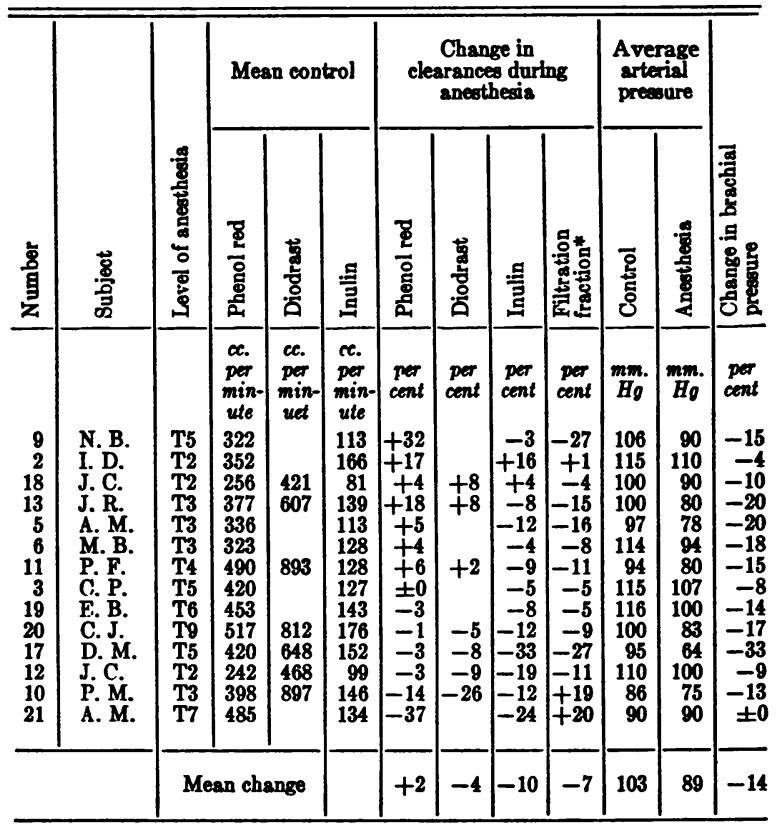

* Where the diodrast clearance was not measured the filtration fraction is calculated on the assumption that the phenol red/diodrast clearance ratio did not change materially during anesthesia, an assumption justified in theory and substantiated in the 7 cases where both clearances were followed.

subject (Number 9) in Table I, the mean arterial pressure decreased by an average of 15 per cent, which circumstance would be expected to produce a corresponding decrease in renal blood flow; actually, however, the renal blood flow increased by an average of 32 per cent, indicating vasodilatation of either the afferent or the efferent glomerular arterioles, or both; the fact that the filtration fracion decreased by 27 per cent indicates that the renal hyperemia resulted primarily from dilatation of the efferent arterioles.

But the first subject, which we have selected only for the purposes of discussion, is an outstanding exception; only two others showed any evidence of hyperemia (Numbers 2 and 13), the majority showing no change in blood flow, and the last one (Number 21) showing a significant reduction in blood flow which must be attributed to constriction of the renal arterioles (predominantly of the efferent arterioles, since the filtration fraction was substantially increased). Indications of vasoconstriction are also evident in Number 10 .
Taking the series as a whole, the changes in renal blood flow are practically nil; in view of the fact that the renal blood flow can increase by 100 per cent, it is clear that spinal anesthesia has negligible effects upon the renal circulation. We conclude, therefore, that the normal tone of the renal vessels is not significantly dependent upon sympathetic nervous impulses of central origin. ${ }^{2}$ This is not to say that the renal vascular bed has remained unchanged: the maintenance of an essentially constant renal blood flow in most subjects in the face of reduced arterial pressure implies vascular dilatation of some degree to offset the fall in arterial pressure. But it is, of course, impossible to suppose that this dilatation is in any way dependent upon the central nervous system during spinal anesthesia. Although the slight alterations in blood flow observed after denervation, both in the direction of increased and decreased flow, may be interpreted as evidences of the abolition of slight vasoconstrictor or vasodilator tone of central origin, superimposed upon the peripheral autonomous bed, they may also represent spontaneous changes in this bed brought about by unidentified local or humoral influences.

It is possible to assume that the renal vascular bed acquires autonomy de novo only as a consequence of denervation, but in view of the rapidity and smoothness of anesthetic denervation any such assumption seems quite superfluous.

\section{Effects of anesthesia on arterial blood pressure}

For the discussion of the effects of anesthesia on the arterial blood pressure we have selected for illustration in Figures 3 and 418 subjects in whom anesthesia reached at least as high as the nipple (T5) and in whom there was complete block of the motor fibers to the lower extremities, abdomen, and thorax. We will consider first the changes in blood pressure effected by anesthesia, apart from the application of the various circulatory tests, as described in the next section. In brief, in 2 out of 18 subjects (Numbers 1 and 2),

2 Berglund, Medes, Benson, and Blumstein (6) report a marked fall in creatinine clearance in two subjects with essential hypertension during spinal anesthesia. But since there was a marked reduction in urine flow and since the bladder was not washed out, the fall in creatinine clearances may have been somewhat less than the recorded figures. 


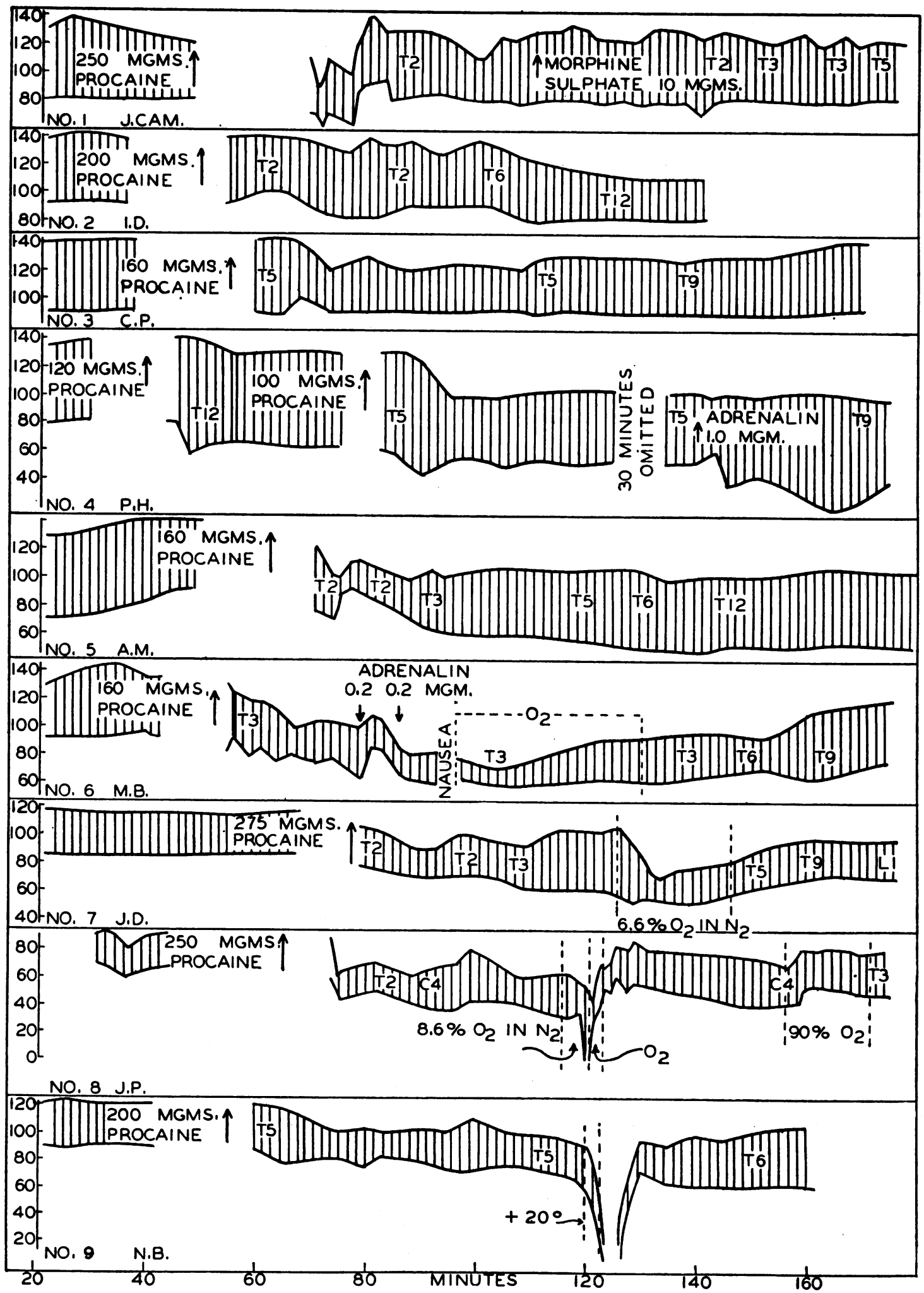

Fig. 3. The Effects of Spinal Anesthesia on Brachial Blood Pressure. Subjects 1 to 9

The figures within the blood pressure curves show the spinal level of complete sensory anesthesia.

Adrenalin was administered subcutaneously in small doses in Number 6 and had no marked effect. In Number $4,1.0 \mathrm{mgm}$. of adrenalin subcutaneously caused a fall in diastolic pressure, as would be expected from the predominantly vasodilating action of this drug; this result, however, is here complicated by the receding anesthesia. Morphine was administered subcutaneously once only (Number 1) and had no effect on blood pressure.

The various circulatory tests are described in the text. 


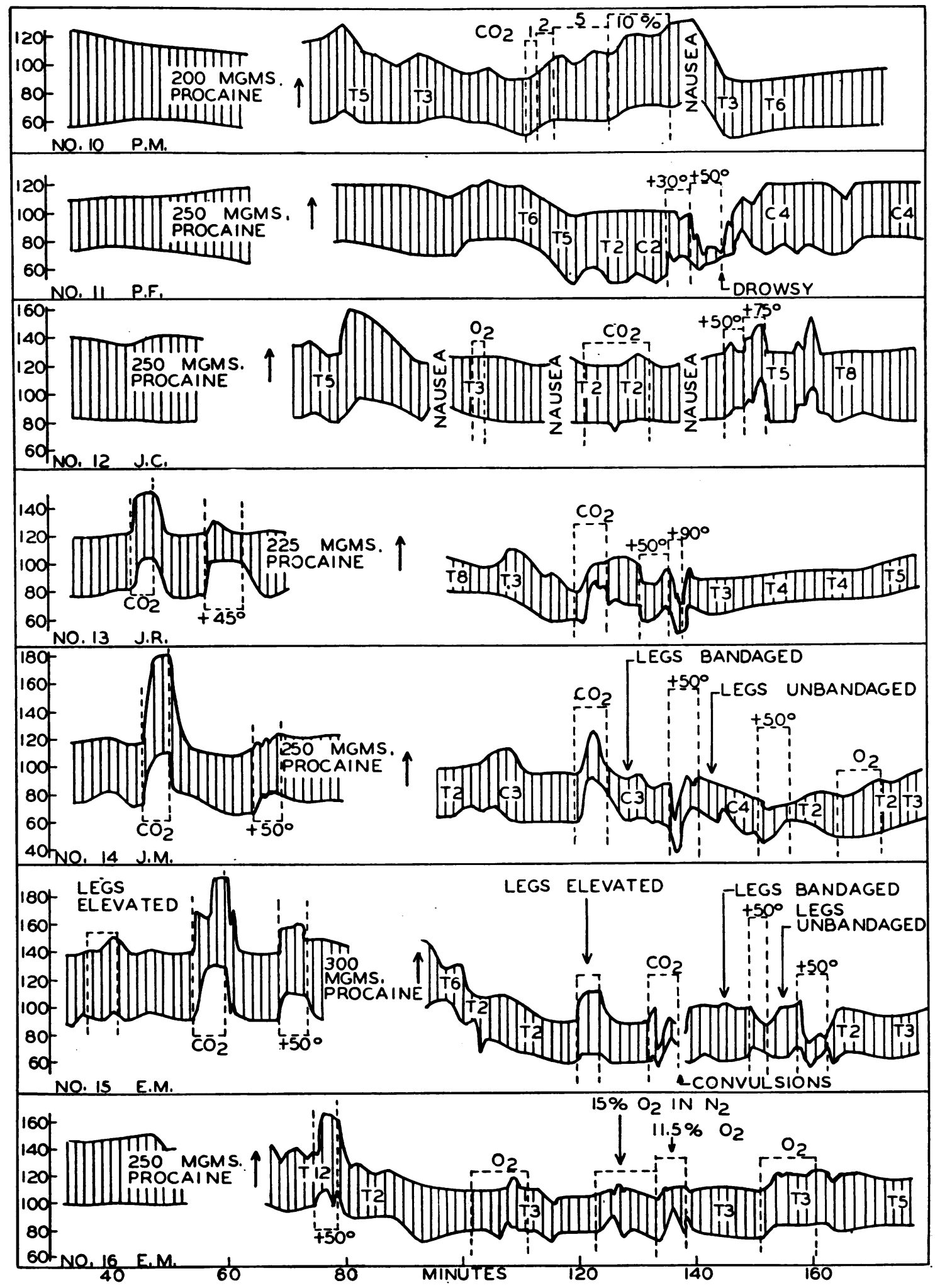

Fig. 4. Subjects 10 to 16

Legend as in paragraph 1 under Figure 3. 
in both of whom anesthesia extended up to T2, the systolic and diastolic pressures were maintained at levels equal or superior to the preanesthesia control period. (Note that in Number 2, the systolic pressure fell only as the anesthesia receded.) In the remaining 16 subjects there was some decrease in either the systolic or diastolic pressure, or both. The systolic pressure fell more than the diastolic in every instance except Number 18. In all but 5 instances (Numbers $4,5,8,11$, and 17) the diastolic pressure was maintained at $60 \mathrm{~mm}$. $\mathrm{Hg}$ or above, and frequently it did not fall below its control value (Numbers 1, 2, 3,10, and 12). The changes in systolic and diastolic pressures are not suited to summary description, but the average pressures are tabulated in Table I.

The type of blood pressure response observed here is, from the point of view of hemodynamics, not consonant with arteriolar dilatation. The fact that the diastolic pressure may not fall at all, that it rarely falls below $60 \mathrm{~mm}$., and that it invariably falls less than the systolic pressure, is directly opposed to the changes to be expected during arteriolar dilatation. Excluding for the moment any volume changes in the post-arteriolar bed, arteriolar dilatation must in principle reduce the peripheral resistance, and therefore, at a constant cardiac output, it will reduce the diastolic pressure; as arteriolar dilatation progresses the diastolic will fall to proportionally lower levels until stagnation in the enlarged arterioles precipitates peripheral circulatory failure. Moderate arteriolar dilatation, by increasing the vascular volume, will also lower the systolic pressure, but not to the same degree as the diastolic, and it therefore will reveal itself in its moderate stages by a substantial increase in pulse pressure at the expense of the diastolic pressure. Insofar as increased capillary volume results from arteriolar dilatation it can only affect this picture by exaggerating these changes. Opposed to the tendency of arteriolar dilatation to lower the systolic pressure will be any increase in cardiac output which may result from increased venous pressure, and it is conceivable that with moderate dilatation this pressor factor could nearly balance the depressor factors, so that the systolic pressure would be well maintained. ${ }^{3}$

\footnotetext{
${ }^{3}$ Perhaps the best examples of arteriolar dilatation are afforded by the action of adrenin and ephedrine,
}

The responses recorded in Figures 3 and 4 are rather those to be expected where the peripheral resistance has remained unchanged, but where the cardiac output has been reduced. During spinal anesthesia the heart rate typically remains constant (60 to 70 ) in unmedicated subjects, at a slightly lower rate than during the control period (70 to $80)$; other factors remaining equal, increased stroke volume would probably prevent any decrease in cardiac output, and, to account for the reduction in arterial pressure we are forced to look for a decreased stroke volume occasioned by a decreased venous pressure. The most likely factors tending to decrease venous pressure in these subjects are dilatation of capillaries, venules, and veins in the skeletal muscles, not in consequence of the abolition of vasotonic impulses, but simply in consequence of the loss of skeletal muscle tone. It may be that additional venous stagnation occurs in the abdomen in consequence of paralysis of the abdominal muscles, and also in consequence of the loss of the reciprocal tonic relationship between the abdominal and thoracic muscles, though the contribution of these factors is uncertain. That the skin arterioles are dilated during spinal anesthesia is reliably indicated by the fact that the skin temperature usually rises, and by plethysomographic measurements (see Section 3 ) ; although this dilatation would of course contribute to the expansion of the vascular bed, it would also tend to elevate venous pressure and offset such venous stagnation as may have occurred."

which lower the peripheral resistance and raise the systolic pressure by increasing cardiac output, chiefly through increasing the venous pressure (the constriction of the skin arterioles and perhaps the veins compensating for the enlarged vascular bed in dilated areas). For illustrations of the action of adrenin or ephedrine on blood pressure in man the reader is referred to the latter part of Number 4 in Figure 3 of this paper, or to Figure 6 of Chasis et al. (18), and to the measurements of cardiac output and peripheral resistance by Starr, Gamble, Margolies, Donal, Joseph, and Eagle (97), Böger, Deppe, and Wezler (8), Wezler and Böger (105a) and Meyer and Spiegelhoff (67a).

4 CoTui (20) has shown that during spinal anesthesia in the dog the spleen may expand by an amount equal to one per cent of the body weight, or roughly $12.5 \mathrm{per}$ cent of the blood volume, while Barcroft and Elliott (5) report that the splenic volume may change by an amount in excess of 10 per cent of the blood volume. Some splenic dilatation in man during spinal anesthesia appears 
Relatively moderate hemorrhage cannot be tolerated by an animal in which compensatory vasoconstriction is prevented by sympathectomy or spinal anesthesia; a loss of 15 per cent of the blood volume may reduce the blood pressure to critically low levels, and a loss of 20 per cent may be lethal $(82,14,56)$. Expansion of the capillaries, venules and veins of the flaccid muscles, and of the abdominal veins, would be equivalent in a subject with vasomotor paralysis below $\mathrm{T} 5$ to a hemorrhage of this magnitude; with no arteriolar dilatation other than in the skin to offset this stagnation by raising venous pressure, the cardiac output would unquestionably be reduced sufficiently to lower the arterial pressure to the extent observed. The reduction of cardiac output need be of no great magnitude, since vasoconstriction in the arms and head could offer but negligible compensation in maintaining the arterial pressure in the face of the decreased cardiac output.

We suggest, therefore, that the fall in blood pressure in spinal anesthesia results, not from arteriolar dilatation, but from a reduction in cardiac output in consequence of venous stagnation. This is essentially the interpretation offered by Gray in 1909 (37) and by Gray and Parsons in 1912 (38), who were the first to consider this problem critically, and for our emphasis upon the venous side of the circulation a precedent has long been established by Yandell Henderson (45). As will be shown later, there is little evidence that arteriolar dilatation occurs, and much evidence that it does not.

\section{The effects of anesthesia on the reflex responses to posture, hypercapnia, and anoxia}

Posture. Since it is known that sensory fibers are more readily blocked by local anesthetics than are motor fibers (33), it was necessary to inquire whether the vasomotor fibers in the anterior roots of our subjects were actually anesthetized. To obtain information on this point we utilized the reflex responses to posture and $\mathrm{CO}_{2}$.

to be the rule, though precise information on this point is lacking. Although hemodynamically the spleen may play a rôle comparable to a major arteriovenous fistula (60), the possible importance of its dilatation in increasing the volume of the post-arteriolar bed cannot be overlooked.
When the normal subject assumes the upright posture, reflex vasoconstriction, mediated through the aortic arch-carotid sinus receptors and the bulbar reflex centers, serves to maintain the arterial pressure with but little change. (See control observations on Numbers 13, 14, and 15.) In our subjects with spinal anesthesia, bending the body at the waist to an angle of $50^{\circ}$ had little effect on the arterial pressure (Numbers 12 and 13), while an angle of $75^{\circ}$ produced a slight rise in pressure in Number 12 and an angle of $90^{\circ}$ produced a fall in pressure in Number 13. In Number 11 the diastolic pressure was maintained but the pulse pressure thinned out in the manner characteristic of a failing venous return. Only in one instance (Number 9) did slight elevation $\left(20^{\circ}\right)$ lead to syncope, ${ }^{5}$ but it is probable that none of our subjects could have tolerated the upright position for long without syncope, for progressive failure of the circulation would most certainly have occurred. We endeavored to determine the effect on the blood pressure of tightly bandaging the legs with an Esmarch bandage during tilting (Numbers 14 and 15) but the results were indeterminate, apparently as much stagnation occurring in the abdomen as in the legs.

The above observations demonstrate that the characteristic responses to gravity, namely, a rise in diastolic pressure and a well maintained systolic pressure, were absent in our subjects, indicating that the vasomotor pathways were effectively blocked. ${ }^{\circ}$ The observed responses are not such as are to be expected if there is maximal dilatation of the vascular bed, in which circumstance immediate syncope should almost certainly occur. On the contrary, they suggest moderate capillaryvenous stagnation, aggravated by gravity.

Hypercapnia. In normal animals and man the inhalation of gas mixtures containing $\mathrm{CO}_{2}$ produces an abrupt rise in both systolic and diastolic pressure, this reflex response being mediated in part through the carotid receptors, and in part

\footnotetext{
s Interestingly, this was the subject who showed renal hyperemia (see Table I).

- What appears to be a reflex response to tilting was obtained in Number 16, but here the level of anesthesia was only up to $\mathrm{T} 12$ at the time of tilting; although we may presume that the legs could not participate in this response, the major splanchnic vasomotor paths were still intact.
} 
through the bulbar centers. Ten per cent $\mathrm{CO}_{2}$ is sufficient to produce a maximal effect $(42,57$, 59, 64, and 75). Our gas mixtures were prepared by using an anesthetic appliance equipped with accurate metric flow meters and were not analyzed in every case, but from the analyses of some of them we can state that they ranged from 10 to 14 per cent. In Numbers 13, 14, and 15 the subject was tested with $\mathrm{CO}_{2}$ immediately before anesthesia to demonstrate that he gave the typical normal response. Two features in this normal response are to be noted: the rise in blood pressure occurs immediately, and the pressure remains at a maximal value so long as hypercapnia persists. ${ }^{7}$ As demonstrating the response of subjects with high spinal anesthesia to hypercapnia we call attention to Numbers $10,12,13,14$, and 15 in Figure 4, and to 17 and 18 in Figures 1 and 2. $\mathrm{CO}_{2}$ may sometimes cause a rise in pressure, but the rise is slow and progressive (Number 10) or slow and transient, disappearing during the hypercapnia (Number 14). More frequently the response consists of a distortion of the pulse pressure without a significant rise in mean pressure (Numbers 13,15,17, and 18). In one subject (Number 12) 10 per cent $\mathrm{CO}_{2}$ had absolutely no effect on the blood pressure.

It is to be emphasized that these high concentrations of $\mathrm{CO}_{2}$ produce an extreme hyperpnea which must profoundly influence cardiac filling; it is to be expected that the precise effect in any instance will be influenced by the degree of synchronization of the diaphragmatic movements (the intercostal muscles being paralyzed) with the slow heart rate (60 to 70 ) obtaining in these subjects. Further factors influencing the contour of the pulse pressure under $\mathrm{CO}_{2}$ are the possible vasoconstriction in the unanesthetized head, arms, and hands, mediated through the upper thoracic segments, and the pressure of the diaphragm upon the abdominal viscera, in consequence of its extreme excursions. Moreover, there may be small quantities of sympathin $\mathrm{E}$ thrown into the general circulation from such upper thoracic sympathetic fibers as are still intact, and this hormone may

7 We fully realize that the brachial pressures as measured by auscultation are not accurate measures of the intra-arterial pressures, but the qualitative changes and mean value unquestionably follow the true values closely enough to warrant the conclusions drawn here. cause slight vasoconstriction elsewhere in the body. The variety of changes in blood pressure which we observe under $\mathrm{CO}_{2}$ we would attribute to these causes, and chiefly to the effect of the hyperpnea on cardiac filling. In no case does the character of the blood pressure response to $\mathrm{CO}_{2}$ in the anesthetized subject reproduce the normal reflex response. We believe, therefore, that the $\mathrm{CO}_{2}$ test demonstrates that under the conditions of our observations (anesthetization to T5 or higher with the subject initially in the face down position) the vasomotor pathways emerging below T5 are effectively blocked.

Anoxemia. We have produced anoxemia in three subjects; in Number 7, when anesthesia was at the level of the neck (cervical cord) a $\mathrm{N}_{2}-\mathrm{O}_{2}$ mixture containing 8.6 per cent $\mathrm{O}_{2}$ was administered by a small anesthetic face mask for $18 \mathrm{~min}$ utes; there were slight variations in pulse rate, and this remained at about 70 until the end of the anoxic period. After 11 minutes of anoxia, the subject became apprehensive and began to perspire; at 17 minutes twitching movements appeared about the eyes, and the fingers showed spasm; there was profuse perspiration of palms and face, but no perspiration on the body below the clavicle (i.e., in the anesthetized regions); premature contractions appeared, and the subject. complained of dizziness and became lethargic. Consciousness was not lost and removal of the mask effected prompt relief from the anoxic symptoms. A sample of arterial blood taken just before the end of the anoxic period showed 18.1 volumes per cent $\mathrm{O}_{2}$ capacity, and 8.6 volumes per cent $\mathrm{O}_{2}$ content, or 48 per cent saturation. The systolic pressure in this subject fell, but the diastolic remained unchanged. In Number 16, a $\mathrm{N}_{2}-\mathrm{O}_{2}$ mixture containing about 15 per cent $\mathrm{O}_{2}$ was administered for 8 minutes, after which the $\mathrm{O}_{2}$ content was decreased to 11.5 per cent, this mixture being administered for an additional 5 minutes. No signs of anoxia appeared with the first gas mixture; after 2 minutes with the second mixture cyanosis was evident and premature contractions appeared. The heart rate increased momentarily from 70 to 78 , but was at 70 at the conclusion of the anoxic period. Arterial blood taken at the end of the anoxic period showed 60 per cent saturation, in comparison with 84 per cent saturation in a sample taken just before the anoxic 
period. (The low value of the first sample was unquestionably due to thoracic muscle paralysis.) Again the blood pressure showed no marked changes. In Number 8, a gas mixture containing 8.6 per cent $\mathrm{O}_{2}$ in $\mathrm{N}_{2}$ was administered for 4.5 minutes. After 1 minute the subject became apprehensive and restless; in 2 minutes twitching movements appeared about the eyes and the fingers showed spasm; after rapidly developing cyanosis the subject began to yawn and grit his teeth, and he became drowsy and went into syncope; pure $\mathrm{O}_{2}$ was given under pressure for 2 minutes, during which time the cyanosis cleared and consciousness was recovered. Arterial blood taken before anesthesia showed 12.9 volumes per cent $\mathrm{O}_{2}$ capacity, 12.6 volumes per cent $\mathrm{O}_{2}$ content, or 96 per cent saturation; a second arterial blood sample taken during the period of anoxia and just before syncope showed 13.6 volumes per cent $\mathrm{O}_{2}$ capacity, 5.5 volumes per cent $\mathrm{O}_{2}$ content, or 42 per cent saturation. The response in this subject was complicated by the initially low $\mathrm{O}_{2}$ capacity, which was attributable to anemia. The abrupt nature of the syncope suggests that it was of the vasovagal type, precipitated by cerebral anoxia, but in any case we do not believe that it can be accepted as indicative of the normal response, especially in view of the almost equally severe anoxemia induced in the other two subjects. We did not produce anoxemia in our subjects during control periods, but from the fact that $\mathrm{O}_{2}$ lack is normally accompanied by a rise in blood pressure, our failure to obtain this effect during anesthesia affirms our conclusion that the vasomotor paths were actually blocked. However, the chief value of our observations on anoxia will be brought out in Section 8.

\section{PART II}

\section{Discussion}

If the interpretation given above is correct, it involves the essentially complete abandonment of the view that vasomotor impulses from the central nervous system are necessary, in a subject at rest, to maintain the peripheral arteriolar bed in its normal tonic state, not only in the kidneys but also in the viscera and possibly in the skeletal muscles. In this interpretation we are at variance, not only with nearly all investigators of spinal an- esthesia, who have tacitly or explicitly accepted dilatation of the arterioles of the splanchnic and other regions as the major hypotensive factor (10, $12,13,20,27,56,62,67,81,88,89,94$, and 98 ), but also with the conclusions drawn from numerous animal experiments upon which the accepted idea of the tonic activity of the sympathetic nervous system is founded. In view of this fact it is necessary to examine the contrary evidence critically.

\section{The alleged tonic activity of the vasoconstrictor paths}

The notion of vasotonic activity in the sympathetic nervous system in the normal animal is based largely upon the fact that the blood pressure falls or the peripheral blood flow increases immediately after surgical section of the splanchnic fibers in anesthetized cats and dogs. It must be noted, however, that surgical section of the splanchnic nerves, the lateral ganglia, the anterior roots of the cord, or the cord itself, involves traumatic excitation not only of vasoconstrictor fibers, but also of the vasodilator fibers to the viscera, skin, and skeletal muscles. But what is more important is the fact that such observations have invariably been made in anesthetized animals.

In 1912 Elliott (23) showed that during anesthesia with ether, chloroform, or urethane an intact adrenal gland in the cat may be nearly depleted of its content of adrenin, whereas a denervated gland in the same animal is unaffected. Cattell (17) demonstrated in 1923 that ether anesthesia increased the perfusion pressure and caused a diminution in the volume of a normal limb, but not in a denervated limb, which phenomenon he attributed to excitation of the vasomotor center. More recently, Bhatia and Burn (7) have shown that ether excites both the central and spinal sympathetic centers. Ether also causes constriction of the spleen (44). Evidences of sympathetic excitation in man during ether anesthesia have been listed by Knoefel (61), and so marked is the systemic pressor action of ether that its inhalation or subcutaneous injection has actually been used to elevate the blood pressure during spinal anesthesia $(98,67,1)$. On the other hand, ether anesthesia is accompanied by hyperemia in the hind limb (55), by a decreased $\mathrm{O}_{2}$ A-V difference (right heart blood) in the 
dog (90), by elevation of the skin temperature in man (21), and by other evidences of vasodilatation. Consequently, the overall effect of ether anesthesia is difficult to evaluate since the sympathetic nervous system carries dilator fibers to the viscera as well as to the muscles in the dog, and perhaps also in man. Possibly, as Burn (15) points out, it excites the "vasodilator center" as well as the vasoconstrictor center. It is clear that during ether anesthesia either vasoconstriction or vasodilatation may predominate $;^{8}$ as White (106, p. 121) suggests, splanchnic constriction may occur simultaneously with skin dilatation.

An equally severe arraignment can be levelled against observations made on morphinized animals. Morphine, in addition to slowing the heart by vagal action, depresses the respiratory center and consequently promotes anoxia and hypercapnia (76). It is reported that in sympathectomized cats and dogs the blood pressure is quickly lowered to critical levels by slight degrees of either hypercapnia or anoxia (see Section 4), and it is conceivable that these factors contribute to the marked hypotension which accompanies surgical denervation or spinal anesthesia in morphinizedetherized animals. Furthermore, morphine (and more especially scopolamine) causes relaxation of the skeletal muscles and thus promotes venous stagnation. That the hypotension of spinal anesthesia in dogs is in fact aggravated by morphine, scopolamine, bartiturates, and other anesthetics has been pointed out by Seevers and Waters (89).

In view of the above facts, we may confidently reject the acute effects of denervation on blood pressure or vascular tone, when effected under ether or morphine anesthesia, as having little bearing on the normal animal. In the absence of more information this same criticism must be applied to barbital, amytal, etc., which cause marked dilatation of the spleen (44) and modify many autonomic responses (15), and to urethane, which is known to evoke vasoconstrictor activity (7).

Even excluding the possible effects of the surgical excitation of vasodilator fibers, and of anes-

8 In anesthetized animals small doses of adrenin cause a fall in arterial pressure, a phenomenon not observed in unanesthetized animals (22) or man, and many other physiological inversions under anesthesia could be listed if space permitted. Adrenin may also have a hypotensive action in the sympathectomized dog (105). thetics, there remains the question to what extent the delicate pattern of the vasomotor system and the set of the presumptively autonomous peripheral vasomotor apparatus are caused to depart from normal by the procedures of opening the abdomen and fingering the viscera whereby they may suffer some local excitation, if not traumatic injury, by handling, drying, and chilling.

The sympathetic paths are predominantly vasoconstrictor to the skin; that these dermal paths are tonically active at ordinary temperatures (an activity obviously subserving the regulation of body temperature) is indicated by the facts that the temperature of the skin and particularly of the digits in man and of the foot pads in the dog, and the blood flow in the ear of the rabbit (all regions obviously important in body temperature regulation) are increased by sympathectomy $(20,69$, $106,107)$. But the increased volume of the hand after anesthetic nerve block (30) is scarcely more than might be accounted for by dilatation of the skin arterioles (36) and does not certainly indicate dilatation in the muscles, much less in the viscera.

Spinal anesthesia is reported to increase the rate of flow of perfusion fluid through the femoral and brachial arteries of the dog (13), but these observations are complicated by barbital anesthesia. The most creditable evidence of denervation dilatation in the skeletal muscles is the fact that lumbar sympathectomy produces a permanently increased blood flow in the femoral artery of otherwise normal dogs (thermostromuhr method under local anesthetic $(54,55))$, and the increased flow is larger than probably can be accounted for by dilatation of the vessels of the skin and paw. But there remains the question of whether sympathetic activity is not evoked de novo or considerably exaggerated in conscious but operated dogs upon handling in the laboratory. If so, the control blood flows may be abnormally low. Moreover, the lumbar sympathetic fibers to the muscles of the dog appear to be predominantly vasodilator, as in man $(26,36,15)$ and consequently it would not be expected that transection would result in chronic hyperemia. A re-examination with attention to these questions is needed.

Bradshaw (10) has shown that barbitalized cats with the carotid artery cannulated show a marked fall in blood pressure during spinal anes- 
thesia, whereas sympathectomized cats subjected to the same procedure ten days after operation showed no change in blood pressure. He concluded that the fall in blood pressure in the control cats was due entirely to anesthesia of the vasoconstrictor fibers. But the fact that barbital, in addition to modifying other sympathetic responses, dilates the spleen (44) and relaxes the skeletal muscles, and may conceivably promote anoxia or hypercapnia, casts doubt upon these observations; in the sympathectomized cat no compensation (by sympathetic excitation) could be effected for venous dilatation induced by barbital, as in the controls.

Shaw, Steele, and Lamb (91) have worked with dogs which received only local anesthesia for cannulation of the vena cava and femoral artery, and fleeting general anesthesia with ethyl chloride during the intrathecal injection of large doses (10 to $20 \mathrm{mgm}$. per $\mathrm{kgm}$.) of procaine. Though these investigators were not concerned with the present issues, their experiments are impressive from the physiological point of view. After spinal anesthesia in one dog the blood pressure remained unchanged, in another it increased, while in five others, during the first 30 minutes, it fell by an average of 37.5 per cent of the control value. These investigators find (as had been demonstrated by CoTui (20)), that the $\mathrm{O}_{2} \mathrm{~A}-\mathrm{V}$ difference (right heart blood) is invariably increased (because of a fall in the $\mathrm{O}_{2}$ content of venous blood), a result entirely opposite to what occurs in ether anesthesia (90). Under the presupposition that vasodilatation is the cause of the fall in blood pressure, Shaw and his coworkers were forced, in order to explain the paradoxically increased $\mathrm{O}_{2} \mathrm{~A}-\mathrm{V}$ difference, to assume that arteriolar dilatation had caused the blood to stagnate in the anesthetized regions. Their data are open to another interpretation: the increased $\mathrm{O}_{2} \mathrm{~A}-\mathrm{V}$ difference could well be the result of a decreased cardiac output; and, in fact, the parenthetical mention by these investigators of the existence in their dogs of pulmonary ischemia and of decreased circulation time support this explanation.

If vasodilatation were the cause of the hypotension of spinal anesthesia it should, when the arterial pressure is only moderately reduced, be accompanied by an increase in venous pressure and therefore in the stroke volume of the heart.
On the other hand, if venous stagnation is the cause, it should be accompanied by a decreased stroke volume and by a decreased cardiac output.

In dogs Seevers and Waters (89) (barbital) report that the venous pressure is increased by spinal anesthesia, but only one animal is cited in detail, and in this the venous pressure did not increase until the arterial pressure had fallen from 150 to $90 \mathrm{~mm}$. Bower, Clark, Wagoner, and Burns (9) (ether) report no fall in the pressure in the superior vena cava, although the pressure in the inferior vena cava is said to have been decreased. Again in dogs, Burch and Harrison (12) (morphine and barbital) report that an average decrease in blood pressure of 44 per cent is accompanied by an average decrease in cardiac output of 23 per cent. These authors state that the cardiac output is decreased before the blood pressure, but the evidence presented consists of 2 single measurements. In man, Polano (74) reports no change in cardiac output (Broemser's method) in 5 subjects with spinal anesthesia, and a decrease in 2 subjects, but in no case was there a marked drop in blood pressure. In contrast to these results, Schuberth (86) reports cardiac output in 14 subjects (Grollman's method), some of whom had anesthesia as high as the xiphoid or nipples. (All had received $50 \mathrm{mgm}$. of ephetonin before anesthesia.) In 4 subjects the cardiac output increased; in 2 of these the systolic pressure increased, in one it remained unchanged, and in the fourth it fell from 155 to $130 \mathrm{~mm}$. But in the remaining 10 subjects the cardiac output fell, the most marked reduction being associated with the greatest fall in pressure. In all but 3 instances the stroke volume decreased. Schuberth notes the collapsed veins as a sign of reduced venous pressure. $\mathrm{He}$ also reports a consistent fall in cardiac output in rabbits during spinal anesthesia. The venous pressure (auricular) in rabbits was either unchanged or fell; it never increased except under artificial respiration. In both man and rabbits the $\mathrm{O}_{2} \mathrm{~A}-\mathrm{V}$ difference was consistently increased. Schuberth concluded that the fall in arterial pressure was a consequence of decreased cardiac output, following " an impaired return to the heart," but he attributed this impaired return to paralysis of the vasoconstrictor nerves, and does not mention the possibility of pure venous stagnation. Neither he nor Shaw, 
Steele, and Lamb (91) discuss the difficulties of reconciling decreased venous pressure, decreased cardiac output, and increased $\mathrm{O}_{2} \mathrm{~A}-\mathrm{V}$ difference, with the notion of arteriolar dilatation, which, short of circulatory collapse, should tend to increase venous pressure and cardiac output and decrease the $\mathrm{O}_{2} \quad A-V$ difference. Schuberth's control observations did not immediately precede the observations under anesthesia, yet the absolute figures for the cardiac output are so low in a large percentage of the subjects examined by him as to leave no doubt as to their qualitative significance. Accrediting such measurements ${ }^{9}$ after partial or complete thoracic paralysis, a reduced cardiac output, sometimes to a very low level, can be accepted as a fact. This fact, then, combined with the blood pressure picture described here, points conclusively to venous dilatation, rather than arteriolar dilatation, as the cause of the fall in arterial pressure.

\section{The evidence bearing on the autonomy of the peripheral arteriolar bed}

In explaining the hypotension of spinal anesthesia, it may be noted that Nowak (70) has argued in favor of a toxic effect of the anesthetic after systemic absorption, but this explanation seems to have been excluded by the intravenous injection of large doses $(27,9)$. We have observed no evidences of systemic toxicity or central respiratory depression in spite of relatively large doses of procaine intrathecally.

Taking first the evidence obtained by surgical denervation, it has long been known that after spinal transection the blood pressure tends to return to normal levels, the restoration possibly being due, in part, to subsidiary vasomotor centers in the cord $(66,58)$. But the denervated vessels of the ear in the rabbit, of the paws in dogs, etc., and of the hands and feet in man, ultimately recover their normal caliber, demonstrating that even in the skin, where tonic vasomotor activity

9 Neither Seevers and Waters (89) nor Bower et al. (9) discuss the significance of venous pressure measurements relative to the atmosphere before and after paralysis of the thorax, nor consider the effect of position of the animal, which presumably was tied down upon its back. And neither Polano (74) nor Schuberth (86) question the validity of cardiac output measurements by indirect methods during thoracic paralysis. must be accepted, the vascular bed possesses at least a latent capacity for autonomous constriction $(66,32,106,107)$.

The recent observations of Cannon and of Heymans and their respective collaborators $(2,3,4$, $16,73,79,82$ ) have shown that the peripheral vasomotor apparatus can re-establish an essentially normal blood pressure after complete sympathectomy, which appears to destroy all constrictor paths to the splanchnic viscera, skin, and muscles, only the dorsal root dilators and the vagi remaining intact $(101,79,68)$. Rowntree and Adson (80) have reported a subject with polyarthritis in whom the blood pressure returned to normal after cervicothoracic and abdominal ganglionectomy. In all these instances, however, a considerable interval was allowed to elapse after denervation before pressure readings were taken, affording an opportunity for the peripheral vasomotor apparatus to acquire slowly and de novo a degree of autonomous activity perhaps not present in the normal animal. It is, in fact, commonly believed that such is the actual course of events, a belief which rests chiefly upon the observed restoration of arteriolar tone in the denervated ear of the rabbit and the denervated skin in dogs or man.

But against this belief may be presented the evidence afforded by the experiments of Hermann, Morin, and Vial $(46,48,49)$, who have destroyed the thoracic, lumbar, and sacral cord by a technique which permits quick restoration of blood pressure. The pressure is elevated, presumably by vasoconstrictor excitation, at the moment of trauma of the cord, thereafter falling to 70 to 80 $\mathrm{mm} . \mathrm{Hg}$, but it recovers to 110 to $140 \mathrm{~mm}$. shortly after the anesthetic has worn off. After vagotomy these "cervical" dogs show no reflex responses to excitation of the central end of the depressor nerve, the bulb or cervical cord, and it is concluded that no vasomotor connections pass to the periphery except from the spinal cord below T1 (49). Here the restitution of blood pressure might be attributed to the autonomy of the lateral and collateral ganglia, though Hermann, Morin, and Cier (52) adduce evidence that these ganglia play a negligible rôle. In any case, these investigators have fully demonstrated that a pressure of 100 to $140 \mathrm{~mm}$. can be maintained permanently in the dog from a few hours onwards after all con- 
nections with the central nervous system have been destroyed up to $\mathrm{T} 1$.

The most pertinent observations on blood pressure immediately after sympathectomy are those of Grimson, Wilson, and Phemister (40), whose blood pressure readings were taken on unanesthetized dogs 3 days after the last stage of denervation. They report that the blood pressure, which averaged $155 \mathrm{~mm}$. before operation, was lowered by an average of $38 \mathrm{~mm}$. by denervation; there was no decrease in blood volume to explain the lowered blood pressure, nor was there any increase in volume such as might be expected in the event of an appreciable dilatation of the vascular bed. The pulse rate in 3 dogs was slowed by the operation from 109 to 69 , and the minute cardiac output estimated twice before and twice soon after operation in 4 dogs averaged 28 per cent lower postoperatively. The authors say: "The fact that despite the lowered cardiac output and slight bradycardia a blood pressure averaging $117 \mathrm{~mm}$. of mercury was maintained shows that the animals suffered only moderate lowering of peripheral resistance as a result of sympathectomy. This indicates that there is an inherent vascular tone which assists in the maintenance of the blood pressure at a reduced level immediately after sympathectomy." This is a conservative statement, for the reduction in pressure after sympathectomy may be only apparent and due entirely to the fact that the blood pressure in the control animals was elevated by excitement. In fact, Gregg, Eckstein, and Fineberg (39) report that the normal blood pressure of the "well trained" dog approximates $124 / 85 \mathrm{~mm}$. $\mathrm{Hg}$, and Verney and Vogt (105) cite 100 to $120 \mathrm{~mm}$. as the range of mean arterial pressure. These figures are substantially lower than the control figures of Grimson et al. (40) and are at the level of the figures observed in sympathectomized animals.

The observations of Hermann and his collaborators strongly suggest that the autonomy of the vascular bed in the dog, adequately demonstrated in the chronically sympathectomized animal, can carry on within a few hours after denervation. If such is the case, it should be immediately demonstrable after non-traumatic denervation by spinal anesthesia.

So far as man is concerned, it is asserted by surgeons that one of the advantages of spinal an- esthesia lies in the circumstance that the viscera show no hyperemia, neither the intestines nor the uterus bleeding so freely as during inhalation anesthesia. It was from this fact that Gray (37) and Gray and Parsons (38), who were among the first to inquire critically into this problem, asserted that the fall in blood pressure was caused not by arteriolar dilatation but by decreased venous pressure. The anemic appearance of the viscera has sometimes been attributed to reduced blood pressure, but it occurs without appreciable reduction in blood pressure and may equally well be attributed to the contracted state of the viscera, supplemented by normal arteriolar tone.

Bower, Clark, Wagoner, and Burns (9) were unable to demonstrate any increase in the volume of the leg, ileum, or kidney in the dog during spinal anesthesia and rejected the possibility of vasodilatation. They alternatively attributed the hypotension to respiratory embarrassment, pulmonary congestion, and cardiac failure in consequence of paralysis of the cardiac nerves (?), though the last two factors do not appear to be significant.

It is clear that anesthetic denervation can be effected in the dog without substantial reduction in arterial pressure. We have already referred to the report of Shaw, Steele, and Lamb (91) that the blood pressure does not invariably fall, and Lundy (65) reports no change in blood pressure in two dogs which were maintained by artificial respiration and with complete paralysis, not only of the cord, but also of the cervical and cranial nerves. Seevers and Waters (89), having found that anoxemia reduces the blood pressure in the spinal anesthetized dog, apart from the mechanical movements of the thorax, utilized $\mathrm{O}_{2}$ administration to maintain the pressure and cite an instance in which the pressure was raised in this manner from 120 to $200 \mathrm{~mm}$. (88). In a later paper they report two dogs having control pressures of 144 and $170 \mathrm{~mm}$.; after high spinal anesthesia the pressure was maintained during artificial respiration with a modified Drinker respirator at 150 and $180 \mathrm{~mm}$., although it had previously been reduced to low levels in an interval when there was respiratory paralysis. They state that cord section at T5, or anesthesia up to this level, results only in the slight drop of 5 to $10 \mathrm{~mm}$. in systolic pressure; the tendency for hypotension to appear 
with anesthesia above this level they attribute to anoxia resulting from intercostal paralysis, an interpretation which has also been offered by Heymans, Bouckaert, and Bert (56). None of the investigators mentioned have taken into account the possibility that tying a cat or dog down upon its back with the legs extended might seriously embarrass the venous circulation. It is difficult to imagine circumstances that would equally embarrass the venous circulation in man.

Consideration of the above evidence leads us to believe that in the dog the peripheral arterioles are capable of maintaining a normal blood pressure, as defined by Gregg, Eckstein, and Fineberg (39) and by Verney and Vogt (105) in trained animals, after either destruction of the cord or rapid nontraumatic anesthetic denervation. Consequently, it is to be inferred that basal arteriolar tone in the dog is not dependent upon the tonic activity of the sympathetic nervous system, and it seems highly probable that this is also true in the cat.

\section{Evidence of the autonomous control of the renal vascular bed}

Our conclusion that the renal vascular bed is endowed with autonomous activity is supported by numerous observations on the renal blood flow in the dog, as measured by means of the Rein thermostromuhr. However, with few exceptions these observations have been made on dogs which were anesthetized with ether, morphine, pernocton (sodium butyl- $\beta$-bromallyl barbiturate), chloralose or urethane; the abdomen had been opened and the renal artery or vein dissected free and cleaned in order to put the thermostromuhr in place; frequently artificial respiration has had to be used, and a few investigators report that some of their preparations have had to be discarded because bf anuria. All these circumstances argue against the physiological significance of the results. It may also be noted that Enger and Gerstner (24) report that a vasopressor principle appears in the blood in consequence of momentary renal ischemia; Enger, Linder, and Sarre (25) report that the blood pressure begins to rise within 1 hour after partial clamping of the renal artery, while Verney and Vogt (105) report a rise in 20 to 30 minutes. Whether this rapidly developing constriction involves the renal circulation itself has not been determined, but it is possible that it does.
In many investigations physiological significance has been attributed to changes in renal blood flow observed after some hours of experimentation, the results being equally accredited whether the actual blood flow was 1.0 or $5.0 \mathrm{cc}$. per gram of kidney per minute. It is to be inferred that the finer adjustments of the renal circulation are seriously modified if not wholly obscured by the extremely unphysiological conditions under which most of the thermostromuhr observations have been made; nevertheless, these observations all agree in indicating that the renal circulation of the dog enjoys a remarkable degree of autonomy.

The renal blood flow tends to remain unchanged during hemorrhage (77) and during the increased or decreased blood pressure elicited by pressure changes in the carotid sinus or by administration of $\mathrm{CO}_{2}$ or adrenin $(43,95,96,72,102,83,84)$. The independence of the renal circulation in the face of changing arterial pressure persists after denervation $(43,72)$. It would seem to be in line with this autonomy that the threshold of the renal vessels for adrenin is much higher than in those vessels in the leg (skin and foot pads?) which are constricted by this hormone (43). Though the kidney does not show "reactive hyperemia" (99), a very significant compensation occurs to renal ischemia : when the renal artery is partially closed, the renal blood flow is only momentarily decreased, shortly returning towards normal, and in order to maintain the blood flow at a reduced level the clamp must be repeatedly tightened. This phenomenon has been described independently by Schroeder and Cohn (85) and Enger, Linder, and Sarre (25), and interpreted by them as indicating a local vascular readjustment. The increase in phenol red clearance after clamping the renal artery in the dog, reported by Corcoran and Page (19), is possibly due to this same autonomous dilatation. ${ }^{10}$

Schneider and Wildbolz (83) have shown that acute denervation under morphine-pernocton anesthesia leads, after a short period of ischemia, to a slow but marked increase in blood flow (65 to 145 per cent above the control). Herrick, Essex, and Baldes (53) report an even larger increase after denervation under ether anesthesia. On the

\footnotetext{
10 Similar autonomous vascular readjustments have been reported in the brain (29).
} 
other hand, Handovsky and Samaan (41), working with conscious dogs (but dogs in which the thermostromuhr was attached to the renal artery, and in which the ureters and either the brachial or carotid artery were cannulated), found that splanchnic section under local anesthesia caused a much smaller increase in blood flow (20 to 50 per cent) which, moreover, was transient, lasting only 20 to 50 minutes.

In contrast to the above observations, Rhoads, Van Slyke, Hiller, and Alving (78), measuring the blood flow in an explanted kidney by means of urea $\mathrm{A}-\mathrm{V}$ difference and the urea clearance, found that local anesthesia of the renal nerves in unanesthetized dogs or surgical denervation under ether anesthesia was without consistent effect upon the blood flow. These experiments are open to the criticism that the kidney was already hyperenic, the other kidney having been removed about 2 years previously; and under these conditions it is known that the blood flow through the remaining kidney $(\mathrm{dog})$ is nearly double its normal value (63). We find the renal blood flow in a subject who had had a unilateral nephrectomy 5 years before observation to be nearly as great (1037 cc. per minute) as our average normal figure (1339 cc. per minute). Nearly maximal vascular dilatation might be expected in such a kidney, even though its nervous connections are intact. But apart from this criticism, the results of Rhoads et al. (78) are consonant with our own in indicating no tonic control of the renal circulation in the normal animal.

\section{The vasodilating action of hypercapnia and anoxemia on the peripheral vascular bed}

The pressor response induced in the anesthetized dog and cat by $\mathrm{CO}_{2}$ and anoxemia is converted after section of the vasomotor pathways to a profound depressor reaction. The explanation of this phenomenon is not clear. That $\mathrm{CO}_{2}$ and anoxemia exert a dilating action on arterioles or capillaries in perfused or isolated organs has been repeatedly demonstrated (51), though the application of this evidence to the intact animal is so uncertain that it need not be considered here. But a depressor action is also strikingly evident in intact, denervated preparations. The inhalation of gas mixtures containing from 2 to 10 per cent of $\mathrm{CO}_{2}$ causes a precipitate fall in arterial pressure in ergotamized dogs $(59,71)$, in sympathectomized-vagotomized cats and dogs $(2,3,73)$, in dogs with spinal anesthesia $(56,89,20,87)$ and in cervical dogs with the cord destroyed below $\mathrm{T} 1(47,50,51)$.

The administration of a gas mixture containing 2 to 4 per cent of $\mathrm{CO}_{2}$ to Hermann's " cervical " dogs produces a $10 \mathrm{~mm}$. drop within 2 minutes, while 10 per cent $\mathrm{CO}_{2}$ produces a profound drop in an equal time. Anoxemia has a similar effect: 18 per cent $\mathrm{O}_{2}$ in the respired mixture produces a slight reduction in blood pressure, while 10.5 per cent $\mathrm{O}_{2}$ produces virtual collapse of blood pressure in 1 to 2 minutes' time. (The normal pressor response to anoxemia is first converted to the depressor response when the cord is destroyed up to and including $\mathrm{T} 7$, the depressor response becoming maximal when destruction reaches $\mathrm{T} 3$. It appears therefore that the vasomotor pathways necessary for the normal pressor response emerge below T3, and chiefly in T4-5-6 and 7.) ${ }^{11}$

There appear to be only 3 possible explanations for the depressor phenomenon: (1) $\mathrm{CO}_{2}$ and anoxia may directly or reflexly cause the secretion of some humoral agent which exerts a dilating action on the vascular apparatus; (2) there may be vasodilator fibers emerging from the cord or brain above $\mathrm{C} 6$ which are centrally excited by $\mathrm{CO}_{2}$ and anoxia; (3) $\mathrm{CO}_{2}$ and anoxia may exert a dilating action on the peripheral vasomotor apparatus (arteries, capillaries, or veins) either by direct action on the vascular tissue or indirectly through peripheral neurons. Since there is no evidence to indicate the secretion of a vasodilating humoral agent, and since there is considerable evidence against the existence of vasodilator paths to the viscera emerging above C6 $(49,79)$, the direct action of $\mathrm{CO}_{2}$ and anoxia on the peripheral vasoneural or vascular apparatus appears to be the probable explanation of the fall in pressure. However, if experiments with isolated, perfused organs are excluded, we are aware of no evidence which will enable us to decide whether this dila-

11 (Note added in proof.) Contrary to the above, McDonough (65a) has recently reported that unanesthetized sympathectomized dags, although slightly more sensitive to anoxia than normal dogs, can endure 6 per cent $\mathrm{O}_{2}$ for 5 hours. This observation illustrates the danger of transferring conclusions from anesthetized to normal animals. 
tation involves the arteriolar, capillary, or venous bed.

In any case, we are faced with the paradox that in human subjects with spinal anesthesia up to $\mathrm{T} 3$ or $\mathrm{T} 2$, and in whom all vasomotor reflexes other than those involving the head and arms are demonstrably blocked, neither $\mathrm{CO}_{2}$ nor anoxemia has any depressor action. We administered $\mathrm{CO}_{2}$ in a concentration of 10 per cent for as long as 18 minutes (as in Number 17, Figure 1), or (as in Number 15, Figure 4) to the point where involuntary twitching appeared in the unanesthetized forearms and face, without obtaining any depressing effect upon the circulation. (See also Numbers $10,12,13$, and 14.) Similarly, we are forced to conclude from the responses shown in Numbers 7 and 16 that anoxemia of great severity does not cause dilatation of the peripheral vascular bed in man with high spinal anesthesia. In 3 instances (Numbers 6, 14, and 16) we have administered pure $\mathrm{O}_{2}$; the rise in systolic pressure in Number 6 might have been due to this measure, but in Numbers 14 and 16 the $\mathrm{O}_{2}$ had no marked pressor effect. It has been our experience that $\mathrm{O}_{2}$ relieves the nausea, restlessness, and yawning that signalize bulbar anoxia, but we cannot affirm the conclusion which has been reached in dogs and cats that $\mathrm{O}_{2}$ raises the arterial pressure. We would not particularly expect such an effect since even severe anoxia does not lower the pressure. It must be noted in this connection that Schuberth (86) found no correlation between blood pressure changes and changes in the tidal air of a large series of subjects.

So we are again at variance with the observations on anesthetized dogs and cats, for all of the observations referred to above have been made on anesthetized animals. It may be that the astonishing differences in the innervation of the viscera of the rabbit, hare, cat, dog, and monkey, as described by Burn (15), are presumptive evidence of differences in activity patterns, and, if so, it is clear that studies of the autonomic nervous system and peripheral vasomotor apparatus in other animals must be transferred to man with great caution. That there are species differences in the stability of the peripheral vasomotor apparatus is probable, for the sympathectomized cat suffers an acute fall in arterial pressure and circulatory collapse on slight activity, whereas the sympathectomized dog is extremely competent physiologically, perhaps even more so than the normal animal $(2,4,11,73,31,65 a)$. But, paradoxically, the anesthetized sympathectomized dog is reported to be more sensitive to $\mathrm{CO}_{2}$ than is the anesthetized sympathectomized cat (4). (See footnote 11 on page 335 .)

But anesthesia alters the set of almost every autonomic reflex in the body; it profoundly changes the response of the medullary centers to $\mathrm{CO}_{2}(103,104)$, and it quite possibly alters the response of the peripheral vasomotor apparatus. Until these observations are repeated on unanesthetized animals, and until consideration is given to the effects of posture on the venous circulation in the cat and dog, it would seem premature to accept as proven that there are any major species differences in the reactivity of the arterioles. If these apparent differences are real, we would be inclined to attribute them to the fact of man's bipedal habitus. We may suppose that the pattern of the vasomotor system, both centrally and peripherally, is adapted to his upright posture and it is rather to be expected that the peripheral vascular bed would in its autonomy show greater stability against vasodilating factors, even of a metabolic nature. This suggestion, however, applies primarily to the arterioles: the capillaryvenous circulation, unable to reinforce itself, has remained at a disadvantage, and in man it is possibly more dependent upon skeletal muscle tone and other accessory factors than it is in the quadrupeds.

Our present observations on the importance of dilatation in the post-arteriolar vascular bed in spinal anesthesia add emphasis to the view, long propounded by Yandell Henderson, that the venous side is the weakest portion of the circulatory system.

\section{SUMMARY AND CONCLUSIONS}

Twenty-one normal unoperated subjects have been observed before and during spinal anesthesia. In 18 of these subjects sensory anesthesia was established up to T5, and in 3 subjects to above $\mathrm{T} 1$. That the anterior roots or sympathetic rami have been effectively blocked has been demonstrated by the abolition of the typical reflex responses to hypercapnia, anoxemia, and gravity.

Anesthesia to levels considerably above those at 
which the efferent sympathetic paths to the kidneys emerge from the cord does not produce renal hyperemia, nor does it have any other consistent effect upon the renal circulation. It is concluded that the tone of the renal arterioles is normally maintained by autonomous, intrinsic activity of the peripheral vascular apparatus and is not dependent upon tonic activity of the central nervous system.

Normal blood pressure may be maintained in normal, unoperated subjects with sensory anesthesia at spinal levels (T5 or higher) above those at which the highest vasoconstrictor fibers emerge to the splanchnic viscera and legs. In those instances in which the arterial pressure is reduced, the systolic pressure falls more than the diastolic, the latter being usually maintained at essentially normal levels. There is at no time the hemodynamic picture to be expected from arteriolar dilatation; rather the decrease in blood pressure is such as is to be expected in consequence of a decreased cardiac output in the face of an unchanged arteriolar bed. That the cardiac output is actually decreased is indicated by measurements available in the literature. This decreased cardiac output results from decreased stroke volume, the latter resulting from post-arteriolar dilatation and decreased venous pressure. The post-arteriolar dilatation can be explained in terms of dilatation of capillaries, venules, and veins in consequence of skeletal muscle paralysis, without positing tonic sympathetic activity to these circulatory channels. Possibly some further venous embarrassment is occasioned by paralysis of the abdominal and thoracic muscles, and, in some instances, by acute dilatation of the spleen. Dilatation of the arterioles of the skin, the only region for which there is indubitable evidence of sympathetic tonic activity in man, probably operates against the development of hypotension by contributing to the maintenance of venous pressure.

It is inferred that (like the renal arterioles) the arterioles of the other splanchnic viscera and probably the skeletal muscles possess sufficient autonomy to maintain a normal blood pressure after denervation, providing the method of denervation is not such as to precipitate severe circulatory disturbance. It is a corollary of this conclusion that there is normally negligible tonic activity in the sympathetic vasomotor paths.
The peripheral vasomotor system in man under spinal anesthesia is highly resistant to hypercapnia and anoxemia, which precipitate circulatory collapse in the anesthetized sympathectomized dog and cat and in the anesthetized cervical dog by dilating some as yet undetermined portion of the vascular bed.

Evidence bearing on the tonic activity of the vasomotor system, as obtained from the sympathectomized dog and cat, the cervical dog, and the dog under spinal anesthesia, has been critically reviewed, and it has been pointed out that most of this evidence suffers from having been obtained from anesthetized animals, and reasons have been given for its inadequacy.

It may be emphasized that our conclusion regarding the absence of important tonic activity in the sympathetic vasomotor paths to the arterioles generally, and to the kidneys especially, refers only to normal man in the resting, basal condition, and in the supine position. It remains to be determined to what extent sympathetic activity may be evoked by traumatic excitation, by assumption of the upright posture, by excitement, in hypertensive disease, etc. Investigation of these questions relative to the kidneys is now in progress.

The analysts in this investigation have been Miss Katharine Tilson, Miss Frances Marx, and Miss Norma Finkelstein. We are indebted to Dr. John Adriane for his assistance to Professor Rovenstine and for making the $\mathrm{CO}_{2}$ and $\mathrm{O}_{2}$ analyses.

\section{BIBLIOGRAPHY}

1. Babcock, W. W., Blood pressure in relation to spinal anesthesia. Anesth. and Analg., 1925, 4, 222.

2. Bacq, Z. M., Brouha, L., and Heymans, C., Réactions vasodilatatrices chez l'animal totalement sympathectomisé. Compt. rend. Soc. de biol., 1933, 114, 154.

3. Bacq, Z. M., Brouha, L., and Heymans, C., Les voies centrifuges des réflexes vasomoteurs d'origine sino-carotidienne. Ann. de Physiol., 1933, 9, 807.

4. Bacq, Z. M., Brouha, L., and Heymans, C., Recherches sur la physiologie et la pharmacologie du système nerveux autonome. VIII. Réflexes vasomoteurs d'origine sino-carotidienne et actions pharmacologiques chez le chat et chez le chien sympathectomisés. Arch. internat. de pharmacodyn. et de thérap., 1934, 48, 429.

5. Barcroft, J., and Elliott, R. H. E., Some observations on the denervated spleen. J. Physiol., 1936, 87, 189. 
6. Berglund, H., Medes, G., Benson, T. Q., and Blumstein, A., Effects of spinal anesthesia on glomerular function in hypertension. Acta med. Scandinav., 1935, 86, 292.

7. Bhatia, B. B., and Burn, J. H., The action of ether on the sympathetic system. J. Physiol., 1933, 78, 257.

8. Böger, A., Deppe, B., and Wezler, K., Die Dynamik des menschlichen Kreislaufes unter der Wirkung von Kreislaufmitteln. I. Typische Reactionsabläufe. Arch. f. exper. Path. u. Pharmakol., 1938, $189,480$.

9. Bower, J. O., Clark, J. H., Wagoner, G., and Burns, J. C., Spinal anesthesia. Surg., Gynec., and Obst., 1932, 54, 882.

10. Bradshaw, H. H., The fall in blood pressure during spinal anesthesia. Ann. Surg., 1936, 104, 41.

11. Brouha, L., Cannon, W. B., and Dill, D. B., The heart rate of the sympathectomized dog in rest and exercise. J. Physiol., 1936, 87, 345.

12. Burch, J. C., and Harrison, T. R., The effect of spinal anesthesia on the cardiac output. Arch. Surg., 1930, 21, 330.

13. Burch, J. C., and Harrison, T. R., The effect of spinal anesthesia on arterial tone. Arch. Surg., 1931, 22, 1040.

14. Burch, J. C. Harrison, T. R., and Blalock, A., A comparison of the effects of hemorrhage under ether anesthesia and under spinal anesthesia. Arch. Surg., 1930, 21, 693.

15. Burn, J. H., Sympathetic vasodilator fibres. Physiol. Rev., 1938, 18, 137.

16. Cannon, B., The effects of progressive sympathectomy on blood pressure. Am. J. Physiol., 1931, 97, 592.

17. Cattell, McK., Studies in experimental traumatic shock. VI. The action of ether on the circulation in traumatic shock. Arch. Surg., 1923, 6, 41.

18. Chasis, H., Ranges, H. A., Goldring, W., and Smith, H. W., The control of renal blood flow and glomerular filtration in normal man. J. Clin. Invest, 1938, 17, 683.

19. Corcoran, A. C., and Page, I. H., Observations on the relation of experimental hypertension to renal clearance and renal ischemia. Am. J. Physiol., 1938, 123, 43.

20. CoTui, Spinal anesthesia. The experimental basis of some prevailing clinical practices. Arch. Surg., 1936, 33, 825.

21. Craig, W. McK., Horton, B. T., and Sheard, C., Thermal changes in peripheral vascular disease during sympathetic ganglionectomy under general anesthesia. Proc. Staff Meet., Mayo Clin., 1932, 7, 537.

22. Dragstedt, C. A., Wightman, A. H., and Huffman, J. W., The hemodynamic action of minimal effective doses of epinephrine in the unanesthetized dog. Ám. J. Physiol., 1928, 84, 307.

23. Elliott, T. R., The control of the suprarenal glands by the splanchnic nerves. J. Physiol., 1912, 44, 374.

24. Enger, R., and Gerstner, H., Der Einfluss der Niere auf den Blutdruck nach ihrer völligen Lösung aus dem Gewebszusammenhang des Organismus. Ztschr. f. d. ges. exper. Med., 1938, 102, 413.

25. Enger, R., Linder, F., and Sarre, H., Die Wirkung quantitativ abgestufter Drosselung der Nierendurchblutung auf den Blutdruck. Ztschr. f. d. ges. exper. Med., 1938, 104, 1.

26. Fatherree, T. J., and Hines, E. A., The blood pressure response to epinephrine administered intravenously to subjects with normal blood pressure and to patients with essential hypertension. Am. Heart J., 1938, 16, 66.

27. Ferguson, L. K., and North, J. P., Observations of experimental spinal anesthesia. Surg., Gynec., and Obst., 1932, 54, 621.

28. Foerster, O., The dermatomes in man. Brain, 1933. 56, 1.

29. Fog, M., Cerebral circulation. The reaction of the pial arteries to a fall in blood pressure. Arch. Neurol. and Psychiat., 1937, 37, 351.

30. Freeman, N. E., The effect of temperature on the rate of blood flow in the normal and in the sympathectomized hand. Am. J. Physiol., 1935, 113, 384.

31. Freeman, N. E., and Rosenblueth, A., Reflex stimulation and inhibition of vasodilators in sympathectomized animals. Am. J. Physiol., 1931, 98, 454.

32. Gask, G. E., and Ross, J. P., The Surgery of the Sympathetic Nervous System. William Wood and Company, New York, 1934.

33. Gasser, H. S., and Erlanger, J., The rôle of fiber size in the establishment of a nerve block by pressure or cocaine. Am. J. Physiol., 1920, 88, 581.

34. Glaser, H., Laszlo, D., and Schürmeyer, A., Uber die Durchblutungsregulation der Niere. Arch. f. exper. Path. u. Pharmakol., 1932, 167, 292.

35. Goldring, W., Clarke, R. W., and Smith, H. W., The phenol red clearance in normal man. J. Clin. Invest., 1936, 15, 221.

36. Grant, R. T., and Pearson, R. S. B., The blood circulation in the human limb; observations on the differences between the proximal and distal parts and remarks on the regulation of body temperature. Clin. Sc., 1938, 3, 119.

37. Gray, H. T., A study of spinal anesthesia in children and infants. Lancet, 1909, 2, 913 and 991.

38. Gray, H. T., and Parsons, L., Blood-pressure variations associated with lumbar puncture, and the induction of spinal anesthesia. Quart. J. Med., 1912, 5, 339.

39. Gregg, D. E., Eckstein, R. W., and Fineberg, M. H., Pressure pulses and blood pressure values in unanesthetized dogs. Am. J. Physiol., 1937, 118, 399.

40. Grimson, K. S., Wilson, H., and Phemister, D. B., The early and remote effects of total and partial paravertebral sympathectomy on blood pressure. Ann. Surg., 1937, 106, 801. 
41. Handovsky, H., and Samaan, A., Observations on the renal circulation and secretion in the dog, with special reference to the effect of pituitary (posterior lobe) extract. J. Physiol., 1937, 89, 14.

42. Hardgrove M., Roth, G. M., and Brown, G. E., The pressor reaction produced by inhalation of carbon dioxide; studies of patients with normal blood pressure and with hypertension. Ann. Int. Med., $1938,12,482$.

43. Hartmann, H., Ørskov, S. L., and Rein, H., Die Gefässreaktionen der Niere im Verlaufe allgemeiner Kreislauf-Regulationsvorgänge. Arch. f. d. ges. Physiol., 1937, 238, 239.

44. Hausner, E., Essex, H. E., and Mann, F. C., Roentgenologic observations of the spleen of the dog under ether, sodium amytal, pentobarbital sodium and pentothal sodium anesthesia. Am. J. Physiol., 1938, 121, 387.

45. Henderson, Y., Muscle tonus and anesthesia. Anesth. and Analg., 1937, 16, 43.

46. Hermann, H., Morin, G., and Vial, J., Modifications de la pression artérielle au cours et après la destruction progressive de la moelle épinière chez le chien. Compt. rend. Acad. d. Sc., 1934, 199, 487.

47. Hermann, H., Morin, G., and Vial, J., Démonstration péremptoire de l'action vasodilatatrice périphérique du sang asphyxique. Compt. rend. Soc. de biol., 1934, 117, 927.

48. Hermann, H., Morin, G., and Vial, J., Les effets immédiats et lointains de la destruction de la moelle chez le chien. Compt. rend. Soc. de biol., 1934, 117, 967.

49. Hermann, H., Morin, G., and Vial, J., Evolution de la pression artérielle chez le chien privé de sa moelle dorsale, lombaire et sacrée. Compt. rend. Soc. de biol., 1935, 118, 880.

50. Hermann, H., Morin, G., and Vial, J., Influence de l'acapnie et de l'hypercapnie sur les appareils vasomoteurs périphériques. Compt. rend. Soc. de biol., 1935, 118, 1446.

51. Hermann, H., Morin, G., and Vial, J., Composition gazeuse du sang et appareils vasomoteurs. II. Action sur les appareils périphériques, essai de synthese. Ann. de Physiol., 1936, 12, 255.

52. Hermann, H., Morin, G., and Cier, J., Sur l'activité vaso-tonique des ganglions de la chaine sympathique. Documents recueillis sur la chien à moelle détruite. Ann. de Physiol., 1937, 13, 316.

53. Herrick, J. F., Essex, H. E., and Baldes, E. J., Observations on the flow of blood of the kidney. Am. J. Physiol., 1932, 99, 696.

54. Herrick, J. F., Essex, H. E., and Baldes, E. J., Observations on the blood flow in the femoral artery in the dog eight to thirty-four months following lumbar sympathectomy. Proc. Staff Meet., Mayo Clin., 1932, 7, 711.

55. Herrick, J. F., Essex, H. E., and Baldes, E. J., The effect of lumbar sympathectomy on the flow of blood in the femoral artery of the dog. Am. J. Physiol., 1932, 101, 213.

56. Heymans, C., Bouckaert, J. J., and Bert, P., Mécanisme du collapsus circulatoire. Influences sur les réflexes circulatoires sinocarotidiens. Compt. rend. Soc. de biol., 1933, 112, 715.

57. Heymans, C., Bouckaert, J. J., v. Euler, U. S., and Dautrebande, L., Sinus carotidiens et réflexes vasomoteurs. Arch. internat. de pharmacodyn. et de thérap., 1932, 43, 86.

58. Heymans, C., Bouckaert, J. J., Farber, S., and Hsu, F. Y., Spinal vasomotor reflexes associated with variations in blood pressure. Am. J. Physiol., 1936, 117, 619.

59. Heymans, C., Nowak, S. J. G., and Samaan, A., Sur l'action vasomotrice réflexe, centrale et périphérique de l'acide carbonique, de l'anoxémie et de l'asphyxie. Compt. rend. Soc. de biol., 1934, $117,248$.

60. Holman, E., The significance of temporary elevation of blood pressure following splenectomy, with particular reference to the role of the spleen as a regulator of the circulation. Surgery, 1937, 1, 688.

61. Knoefel, P. K., Anesthesia and the sympathetic nervous system. Anesth. and Analg., 1936, 15, 137.

62. Labat, G., Regional Anesthesia. Nelson's Loose Leaf Surgery. Thomas Nelson and Sons, New York, 1931.

63. Levy, S. E., and Blalock, A., The effects of unilateral nephrectomy on the renal blood flow and oxygen consumption of unanesthetized dogs. Am. J. Physiol., 1938, 122, 609.

64. Ludwig, W., Untersuchungen zur Frage der Blutdruckregulation. Arch. f. exper. Path. u. Pharmakol., 1932, 160, 302.

65. Lundy, J. S., Adequate and properly controlled artificial respiration for surgical patients by means of a new pulmonary ventilator. Proc. Staff Meet., Mayo Clin., 1932, 7, 225.

65a. McDonough, F. K., Homeostasis in the sympathectomized dog. Am. J. Physiol., 1939, 125, 530.

66. McDowall, R. J. S., The nervous control of the blood vessels. Physiol. Rev., 1935, 15, 98.

67. Maxson, Louis H., Spinal Anesthesia. J. B. Lippincott Co., New York, 1938.

67a. Meyer, F., and Spiegelhoff, W. Der Einfluss peripher angreifender Kreislaufmittel auf Hersleistung, arteriellen Windkessel und Strömungswiderstand. Arch. f. exper. Path. u. Pharmakol., 1938, 190, 256.

68. Mitchell, G. A. G., The innervation of the kidney, ureter, testicle, and epididymis. J. Anat., 1935, 70, 10.

69. Morton, J. J., and Scott, W. J. M., Studies on the activity of the lumbar sympathetic nervous system. Ann. Surg., 1930, 92, 919.

70. Nowak, S. J. G., The urinary excretion of novocain after spinal anesthesia and the theory of toxic absorption. Anesth. and Analg., 1933, 12, 232. 
71. Nowak, S. J. G., and Samaan, A., The effect of adrenaline, anaemia and carbon dioxide on the vasomotor centre. Arch. internat. de pharmacodyn. et de thérap., 1935, 51, 463.

72. Opitz, E., and Smyth, D. H., Nierendurchblutung bei Reizung des Carotis-Sinus. Arch. f. d. ges. Physiol., 1937, 238, 633.

73. Pinkston, J. O., Partington, P. F., and Rosenblueth, A., A further study of reflex changes of blood pressure in completely sympathectomized animals. Am. J. Physiol., 1936, 115, 711.

74. Polano, H., Experimentelle Untersuchungen über das Verhalten des Minutenvolumens des menschlichen Herzens bei Äthernarkose, Lumbalanaesthesia und nach operativen Eingriffen. Deutsche Ztschr. f. Chir., 1933, 239, 505.

75. Raab, W. Die Beziehungen zwischen $\mathrm{CO}_{2}$-Spannung und Blutdruck bei Normalen und Hypertonikern. Beitrag zur Pathogenese der nicht "nephritischen" Hypertonien. Ztschr. f. d. ges. exper. Med., 1929, 68, 337.

76. Rakeiten, N., Himwich, H. .E., and DuBois, D., Morphine acidosis. J. Pharmacol. and Exper. Therap., 1934, 52, 437.

77. Rein, H., and Rossler, R., Die Abhängigkeit der vasomotorischen Blutdruckregulation bei akuten Blutverlusten von den thermoregulatorischen Blutverschiebungen im Gesamtkreislaufe. Ztschr. f. Biol., 1929, 89, 237.

78. Rhoads, C. P., Van Slyke, D. D., Hiller, A., and Alving, A. S., The effects of novocainization and total section of the nerves of the renal pedicle on renal blood flow and function. Am. J. Physiol., 1934, 110, 392.

79. Rosenblueth, A., and Cannon, W. B., A further study of vasodilators in sympathectomized animals. Am. J. Physiol., 1934, 108, 599.

80. Rowntree, L. G., and Adson, A. W., Further studies on the effects of sympathetic ganglionectomy and ramisectomy. J. A. M. A., 1929, 93, 179.

81. Schilf, E., and Ziegner, H., Das Wesen der Blutdrucksenkung bei der Lumbalanästhesie. Arch. f. klin. Chir., 1924, 130, 352.

82. Schlossberg, T., and Sawyer, M. E. MacK., Studies of homeostasis in normal, sympathectomized and ergotaminized animals. IV. The effect of hemorrhage. Am. J. Physiol., 1933, 104, 195.

83. Schneider, M., and Wildbolz, E., Dekapsulation und Enervation der Niere und Nierendurchblutung. Ztschr. f. urol. Chir., 1937, 43, 1.

84. Schretzenmayr, A., Uber kreislaufregulatorische Vorgänge bei der Nierentätigkeit. Ztschr. f. d. ges. exper. Med., 1933, 92, 367.

85. Schroeder, H. A., and Cohn, A. E., Reaction of renal blood flow to partial constriction of the renal artery. J. Clin. Invest. (Proc.), 1938, 17, 515.

86. Schuberth, O. O., On the distribution of the circulation in spinal anesthesia. Acta. chir. Scandir.av., 1936, 78, Supplement 48, 1.
87. Sebrechts, J., Spinal anesthesia: with regulation of dosage and author's technique. Brit. J. Anaesth., 1934, $12,4$.

88. Seevers, M. H., and Waters, R. M., Circulatory changes during spinal anesthesia. California and West. Med., 1931, 35, 169.

89. Seevers, M. H., and Waters, R. M., Respiratory and circulatory changes during spinal anesthesia. J. A. M. A., 1932, 99, 961.

90. Shaw, J. L., Steele, B. F., and Lamb, C. A., Effect of anesthesia on the blood oxygen. I. A study of the effect of ether anesthesia on the oxygen in the arterial and in the venous blood. Arch. Surg., 1937, 35, 1 .

91. Shaw, J. L., Steele, B. F., and Lamb, C. A., Effect of anesthesia on the blood oxygen. II. A study of the effect of spinal anesthesia on the oxygen in the arterial and in the venous blood. Arch. Surg., 1937, 35, 503.

92. Smith, H. W., The Physiology of the Kidney. Oxford University Press, New York, 1937.

93. Smith, H. W., Goldring, W., and Chasis, H., The measurement of the tubular excretory mass, effective blood flow and filtration rate in the normal human kidney. J. Clin. Invest., 1938, 17, 263.

94. Smith, G. G., and Porter, W. T., Spinal anesthesia in the cat. Am. J. Physiol., 1915, 38, 108.

95. Springorum, P. W., Uber die Unabhängigkeit hormonaler und zentralnervöser Diuresehemmung von der Nierengesamtdurchblutung und dem arteriellen Druck. Arch. f. d. ges. Physiol., 1938, 240, 342.

96. Springorum, P. W., and Centenera, D., Die verschiedene Beteiligung beider Nieren an Diureseänderungen und vasomotorischen Reaktionen. Arch. f. d. ges. Physiol., 1937, 239, 440.

97. Starr, I., Gamble, C. J., Margolies, A., Donal, J. S., Jr., Joseph, N., and Eagle, E., A clinical study of the action of 10 commonly used drugs on cardiac output, work and size; on respiration, on metabolic rate and on the electrocardiogram. J. Clin. Invest., 1937, 16, 799.

98. Steel, W. A., Blood pressure maintenance in spinal anesthesia. J. A. M. A., 1925, 84, 79.

99. Stierlen, G., Untersuchungen über die Nierengefässreaktion bei Mangeldurchblutung. Arch. f. d. ges. Physiol., 1937, 238, 727.

100. Theobald, G. W., and Verney, E. B., The inhibition of water diuresis by afferent nerve stimuli after complete denervation of the kidney. J. Physiol., $1935,83,341$.

101. Thomas, C. B., and Brooks, C. M., The effect of sympathectomy on the vasomotor carotid sinus reflexes of the cat. Am. J. Physiol., 1937, 120, 195.

102. Unna, K., Arterieller Druck und Nierendurchblutung. Arch. f. d. ges. Physiol., 1935, 235, 515.

103. van Esveld, L. W., Pharmakologie des Vasomotorenzentrums. I. Der Einfluss einiger Narkotika 
auf die Erregbarkeit des Vasomotorenzentrums für $\mathrm{CO}_{2}$. Arch. f. exper. Path. u. Pharmakol., 1930, 147, 297.

104. van Esveld, L. W., Pharmakologie des Vasomotorenzentrums. II. Der Anteil des Herzens und Vasomotorenzentrums an durch niedrige $\mathrm{CO}_{2}$-Konzentrationen hervorgerufenen Blutdrucksteigerungen. Arch. f. exper. Path. u. Pharmakol., 1930, $147,317$.

105. Verney, E. B., and Vogt, M., An experimental investigation into hypertension of renal origin, with some observations on convulsive "uraemia." Quart. J. Exper. Physiol., 1938, 28, 253.

105a. Wezler, K., and Böger, A., Der arterielle Gesamtwiderstand unter verschiedenartigen Sympathicusreizen. Arch. f. exper. Path. u. Pharmakol., 1937, 187,65 .

106. White, J. C., The Autonomic Nervous System. The Macmillan Company, New York, 1935.

107. White, J. C., Progress in the surgery of the autonomic nervous system. New England J. Med., 1937, 217, 660. 